\title{
Marguerite Duras, Des journées entières dans les arbres
}

\section{Andrea Manara}

\section{(2) OpenEdition}

\section{Journals}

Edizione digitale

URL: http://journals.openedition.org/studifrancesi/948

DOI: 10.4000/studifrancesi.948

ISSN: 2421-5856

Editore

Rosenberg \& Sellier

\section{Edizione cartacea}

Data di pubblicazione: 1 agosto 2015

Paginazione: 406-407

ISSN: 0039-2944

\section{Notizia bibliografica digitale}

Andrea Manara, " Marguerite Duras, Des journées entières dans les arbres », Studi Francesi [Online], 176 (LIX | II) | 2015, online dal 01 août 2015, consultato il 18 septembre 2020. URL : http:// journals.openedition.org/studifrancesi/948 ; DOI : https://doi.org/10.4000/studifrancesi.948

Questo documento è stato generato automaticamente il 18 settembre 2020.

\section{(c) (i) ()}

Studi Francesi è distribuita con Licenza Creative Commons Attribuzione - Non commerciale - Non opere derivate 4.0 Internazionale. 


\title{
Marguerite Duras, Des journées entières dans les arbres
}

\author{
Andrea Manara
}

\section{NOTIZIA}

MARGUERITE DURAS, Des journées entières dans les arbres, édition d'Arnaud RYKNER, Paris, Gallimard, 2012 («Folio Théâtre», 137), pp. 192.

1 La storia di Des Journées entières dans les arbres è quella di una madre che ritorna a Parigi per rivedere il figlio prediletto, Jacques, quello che, da bambino, nella grande proprietà di famiglia in un luogo non meglio specificato dall'altra parte del mondo, passava appunto «des journées entières dans les arbres à contempler les oiseaux» (p. 93), invece che andare a scuola. La donna è ricca (dice), e ritorna con gioielli d'oro e mazzi di banconote. Il figlio invece è un giocatore, perde sistematicamente a carte i pochi soldi che guadagna intrattenendo le clienti del dancing dove lavora con la sua compagna, Marcelle, una entraîneuse senza qualità che finirà col lasciarlo. Anche la madre se ne andrà, di mattino presto, lasciandogli soldi e gioielli che di lì a poco lui si giocherà a carte. Lei non si aspetta più nulla, salvo l'amore che li lega, madre e figlio, divorante, pieno d'orgoglio, al di là di tutto.

2 Poi c'è l'altra storia, quella del testo. Non meno importante, perché è la storia di una scrittura letteraria che diventa teatro e cinema, senza perdere il carattere che le è proprio e che corrisponde anche al sapore di un'epoca, gli anni Sessanta e Settanta, quando si parlava di un vero e proprio "stile Duras": frasi brevi, posture ieratiche, spazi bianchi, e qualcosa di intellettuale e sensuale allo stesso tempo, capace di far diventare carnale il cerebrale, e viceversa. Des journées entières dans les arbres è stato successivamente un racconto (pubblicato da Gallimard nel 1954), una pièce scritta su richiesta di Jean-Louis Barrault e diretta dallo stesso Barrault (rappresentata per la prima volta l'1 dicembre 1965 al teatro dell'Odéon e pubblicata nel 1968 da Gallimard insieme ad altri scritti teatrali dell'autrice nella raccolta Théatre II), e un film diretto da 
Duras stessa nel 1977 (premio Jean Cocteau 1976), girato due anni dopo la ripresa della pièce a teatro. Des journées entières dans les arbres fu il primo successo teatrale di Marguerite Duras, che, a partire da questo momento, dopo aver sfiorato il Goncourt con Un barrage contre le Pacifique nel 1950, e aver scritto la sceneggiatura di Hiroshima mon amour nel 1958, si afferma come autrice in ambito letterario, cinematografico e teatrale, appunto.

3 Le due storie di Des journées entières dans les arbres, quella del ritorno della madre e quella della sua scrittura in riprese successive, si incontrano, o meglio, entrano in risonanza nella presente riedizione del testo teatrale a cura di Arnaud Rykner, che comprende, oltre a una prefazione del curatore, un dossier di note sulla messa in scena, una bibliografia sommaria divisa in sezioni, e un'analisi della riscrittura teatrale del racconto. In particolare, studiando il passaggio dal testo letterario alla scena, con relative modifiche e adattamenti, Rykner suggerisce l'idea che la serie delle tre riscritture di Des journées entières dans les arbres ne faccia «une œuvre inaugurale dans le parcours de l'écrivain», il cui interesse consiste nel mostrarci «comment le style et la matière des œuvres futures s'élaborent discrètement» (p. 144).

4 La discrezione di cui parla Arnaud Rykner a proposito delle riscritture seriali durassiane, ricorda una forma di consapevolezza, o una certa forma di fenomenologia della coscienza del tempo che si può evincere, oltre che dai testi di Duras - «ce qui remplit le temps, c'est vraiment de le perdre» (La Vie matérielle, Paris, P.O.L., 1987, p. 137) - appunto dalla pratica di riscrittura e dalla ripresa di motivi tematici ricorrenti che segna tutta la sua opera e il passaggio da un medium all'altro in particolare. Tutto, in Duras, la storia della madre che ritorna dal figlio e la storia della sua scrittura, funziona infatti come se la cognizione della perdita fosse anche un fondamento, il presupposto per poter costruire. In questo modo, il commento di Rykner a una replica della madre («Eh bien! Qu'y pouvons-nous, petit? Rien. Nous le savons désormais, l'un comme l'autre. Rien», pp. 37-38) diventa un appunto sulla scrittura: «c'est sur ce rien, sur cette impossibilité de rien commencer de nouveau, que la pièce va alors s'édifier, condamnée à une attente vaine, à peine occupée par des 'passe-temps', uniquement rythmée par le retour des repas dont on a vu la nature troublante [...]. Du coup, si rien ne peut advenir, si le temps est condamné à passer [...], le dialogue lui-même n'est plus là tant pour dénouer une action que pour la remplacer» (pp. 15-16).

5 In quest'ottica, appare chiaro, per esempio, come già in Des journées entières dans les arbres ciò che gli studi di drammaturgia analizzano come "relazioni intersoggettive" (rapporti tra soggetti parlanti e in grado di modificarsi reciprocamente) lasci spazio a un'involuzione della parola, allo stesso tempo ripiegata su se stessa e aperta su un terzo termine assente, che non è il partner sulla scena. Anche le didascalie preludono a una pratica che Marguerite Duras svilupperà ulteriormente nelle sue scritture teatrali successive, diventando essenziali per lo spostamento dell'azione in questo altrove indistinto che carica la rappresentazione di un peso nuovo, «qui contrebalance discrètement-aggiunge Rykner-l'ancrage purement autobiographique ou simplement réaliste de l'œuvre. L'essentiel n'est peut-être pas ce qui est dit, mais ce qui porte le dialogue par en dessous [...]. L'essentiel se passe en amont de la parole ellemême, comme si les personnages se réfugiaient dans l'envers du dialogue explicite» (pp.17-18). Come a ribadire, attraverso la duplicità rivendicata di didascalie atte a designare doppi o tripli fondi silenziosi di dialogo, l'intrecciarsi segreto della storia di Des journées entières dans les arbres, quella di una madre che ritorna - e le possibili letture 
autobiografiche che il curatore non manca di menzionare -, con quella della sua scrittura. 